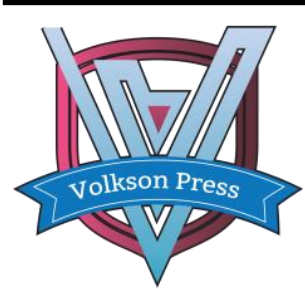

Contents List available at VOLKSON PRESS

Engineering \& Technology Innovations (ETI)

DOI : http://doi.org/10.26480/iceti.01.2017.51.54

\title{
EXPERIMENTAL STUDY ON GYPSUM THERMAL INSULATING MATERIAL
}

\author{
Haiyan Yu,Lei Wang,Yongqiang Li,Jiujun Yang \\ School of Materials Science and Engineering,Tianjin Chengjian University,Tianjin 300384,China \\ *15831662986@163.com
}

This is an open access article distributed under the Creative Commons Attribution License, which permits unrestricted use, distribution, and reproduction in any medium, provided the original work is properly cited

\section{ARTICLE DETAILS}

\section{Article History:}

Received 02 october 2017

Accepted 06 october 2017

Available online 11 october 2017

\section{Keywords:}

desulfurized gypsum; aerated; thermal insulation; thermal conductivity

\section{ABSTRACT}

The gypsum thermal insulation material was prepared by the method of aluminum powder. The effects of high aluminum cement content, aluminum powder content, $\mathrm{NaOH}$ content and mixed water temperature on the performance of gypsum thermal insulation material were systematically studied. The results show that the strength, bulk density and thermal conductivity of gypsum thermal insulation materials are affected by the content of high alumina cement, the content of aluminum powder, the content of $\mathrm{NaOH}$ and the temperature of mixed water. The optimum preparation conditions were as follows: when the content of high-alumina cement was $5 \%$, the content of aluminum powder was $0.7 \%$, the content of $\mathrm{NaOH}$ was $0.5 \%$, the water-cement ratio was 0.6 and the water temperature was $40^{\circ} \mathrm{C}, \mathrm{FGD}$ thermal insulation material has a bulk density of $309.3 \mathrm{~kg} / \mathrm{m}^{3}$, strength of $0.24 \mathrm{MPa}$, thermal conductivity of $0.073 \mathrm{~W} /(\mathrm{m} \cdot \mathrm{K})$.

\section{INTRODUCTION}

Desulfurized gypsum refers to the production of coal combustion flue gas desulfurization purification products obtained, according to our common coal-fired sulfur content calculation, Since 2014, China will discharge nearly a hundred million tons of wet FGD. As a kind of solid waste, the desulphurization gypsum not only occupies the land, depriving it of other uses, but also contains a certain amount of heavy metals and harmful substances, which may enter the bottom with the rainwater, pollute the land and even pollute the groundwater, as a result damages and affects ${ }^{[1-3]}$. Therefore, the use of gypsum as a resource of the current gypsum research.

Desulfurization gypsum is mainly used in the manufacture of gypsum block, gypsum putty, gypsum plaster board and so on. Although the above desulfurization gypsum products have good molding and processing properties, its high thermal conductivity limits its application in the wall insulation materials,so how to improve the insulation properties of gypsum products becomes one of the focus of the current study. Yang Xueteng et al ${ }^{[4]}$ prepared by physical foaming gypsum aerated material, with the foam content of $3.0 \mathrm{ml} / \mathrm{g}$, the product dry density of $308 \mathrm{~kg} / \mathrm{m}^{3}$, compressive strength of $0.13 \mathrm{MPa}$; Zhou Fei et al ${ }^{[5]}$ produced by the method of aluminum powder produced a dry density of $750 \mathrm{~kg} / \mathrm{m}^{3}$, strength of $2.8 \mathrm{MPa}-3.3 \mathrm{MPa}$ of gypsum plaster products. Lao Yousheng ${ }^{[6]}$ and other chemical foam method was prepared under the apparent density of $544 \mathrm{~kg} / \mathrm{m}^{3}$, strength $1.00 \mathrm{MPa}$ of the desulfurization gypsum lightweight wall materials. The previous research mainly focused on the preparation of light gypsum products and physical and mechanical properties, the composition of gypsum products, optimization and insulation properties of the study has yet to be carried out in depth. In this paper, the effects of the preparation process and raw material composition on the bulk density, strength and thermal insulation properties of foaming gypsum were studied, on the basis of coordinating the strength development and gassing speed of gypsum thermal insulation material.

\section{Raw materials and test methods}

\subsection{Experimental Materials}

Desulphurization gypsum: Beijing Huazhuang Building Materials Company, the standard consistency of water consumption is 0.6, initial setting time of $12 \mathrm{~min}$, final setting time of $18 \mathrm{~min}, 2 \mathrm{~h}$ dry strength of 9.2 $\mathrm{MPa}$, chemical composition in Table1;
High alumina cement: Tangshan Liujiu Cement Co., Ltd. production, the chemical composition in Table 2 ;

CaO: Tianjin Sanjiang Co., Ltd., Analytical pure chemical, the content is 5\%, Water reducing agent: Tianjin dragon concrete water reducing agent factory production of polycarboxylate water reducer, content of $0.8 \%$ water reduction rate of $26 \%$;

Aluminum: Tianjin days to build Building Material Co.

$\mathrm{NaOH}$ : Tianjin Guangfu Technology Development Co., Ltd., analytical pure chemicals;

Water: tap water, water to cement ratio of 0.6 .

Table 1 Chemical composition of desulfurized gypsum (\%)

\begin{tabular}{lllllll}
\hline $\mathrm{CaO}$ & $\mathrm{SO}_{3}$ & $\mathrm{SiO}_{2}$ & $\mathrm{MgO}$ & $\mathrm{Al}_{2} \mathrm{O}_{3}$ & $\mathrm{CO}_{2}$ & Others \\
\hline 35.0 & 43.6 & 12.7 & 1.0 & 1.5 & 5.8 & 24 \\
\hline
\end{tabular}

Table 2 Chemical composition of high alumina cement (\%)

\begin{tabular}{lllllll}
\hline $\mathrm{Al}_{2} \mathrm{O}_{3}$ & $\mathrm{SiO}_{2}$ & $\mathrm{Fe}_{2} \mathrm{O}_{3}$ & $\mathrm{CaO}$ & $\mathrm{CO}_{2}$ & $\mathrm{MgO}$ & Others \\
\hline 63.2 & 24.7 & 1.2 & 32.0 & 8.4 & 7.6 & 5.6 \\
\hline
\end{tabular}

\subsection{Test mix design}

The compounding ratio of the test materials is shown in Table 3. Table 3 test mix

High

$\begin{array}{cccccc} & \text { Gypsum } & \text { Alumina } & \mathrm{NaOH} & & \text { Water( } \\ \text { Number } & & & & \text { powder } & \\ & (\%) & \text { Cement } & (\%) & & \left.40^{\circ} \mathrm{C}\right)\end{array}$




\begin{tabular}{lccccc}
\hline S1 & 90 & 5 & 0.5 & 0.7 & 0.6 \\
S2 & 85 & 10 & 0.5 & 0.7 & 0.6 \\
S3 & 80 & 15 & 0.5 & 0.7 & 0.6 \\
S4 & 75 & 20 & 0.5 & 0.7 & 0.6 \\
S5 & 85 & 10 & 0.5 & 0.8 & 0.6 \\
S6 & 85 & 10 & 0.5 & 0.9 & 0.6 \\
S7 & 85 & 10 & 0.5 & 1.0 & 0.6 \\
S8 & 85 & 10 & 0.2 & 0.7 & 0.6 \\
S9 & 85 & 10 & 0.3 & 0.7 & 0.6 \\
S10 & 85 & 10 & 0.4 & 0.7 & 0.6 \\
\hline
\end{tabular}

(a)Effect of the content of high aluminum cement on bulk density and strength of gypsum thermal insulation material

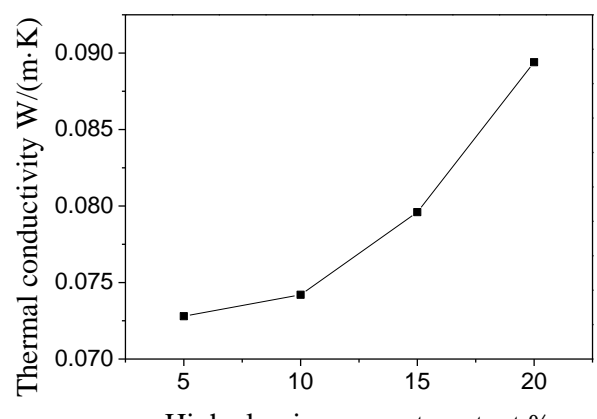

High alumina cement content $\%$

(b)Effect of the content of high aluminum cement on the thermal conductivity of gypsum thermal insulating material

Figure 1. Effect of the content of high aluminum cement on the performance of gypsum thermal insulating material

\subsection{Experimental Methods}

\subsubsection{Preparation process}

FGD gypsum insulation material preparation process is the first dry material according to proportion of weighed and mixed in the mixer evenly, and then added in the dry material with a good $\mathrm{NaOH}$ aqueous solution, high-speed stirring 10s, pouring into the mold, static stop foam , 24 hours after stripping, natural for 28 days.

\subsubsection{Performance testing}

The bulk density and 28-day compressive strength of the product are tested according to GB/T5486-2008 Test Method for Inorganic Hard Adiabatic Products. The size of the specimen is $100 \mathrm{~mm} \times 100 \mathrm{~mm} \times 100 \mathrm{~mm}$. Thermal conductivity of products tested with reference to GB/T10294-2008 thermal insulation materials and the determination of the characteristics of the steady-state protection of hot plate method.

\section{Results and discussion}

In this paper, aluminum powder and $\mathrm{NaOH}$ aqueous solution chemical reaction hydrogen released in the gypsum slurry in the formation of numerous independent bubbles in the gasification process, the slurry will expand, if the slurry hardening quickly, and the foam rate is too slow, Often resulting in too little foam, Small stomatal power generation, the formation of smaller pores, the bulk density and strength of the test block; If the hardening rate of the slurry slow down, and foam is too fast or foam is volume .And the stomatal conductance increased, the formation of stomatal pore size increased, and the connectivity between stomata and stomata easily occurred, leading to the decrease of the bulk density and the strength of the test block. Therefore, in this paper, the following problems are investigated in order to coordinate the hardening rate of gypsum with the rate of gas evolution.

\subsection{Effect of the content of high aluminum cement on the performance of gypsum thermal insulating material}

According to the test mix ratio of S1, S2, S3, S4 in Table 3, select 5\%, 10\%, $15 \%$ and $20 \%$ of high-alumina cement, respectively, and determine the content of high alumina cement to gypsum the bulk density, compressive strength and thermal conductivity of the material, the experimental results shown in Figure 1.

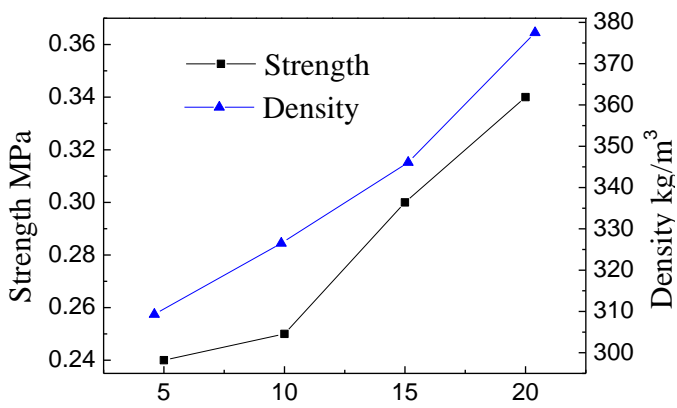

High alumina cement content $\%$

As shown in Fig 1(a), with the increase of the content of high alumina cement, the bulk density and compressive strength of gypsum thermal insulation material increased gradually, the maximum bulk density and the highest compressive strength can reach $377.5 \mathrm{~kg} / \mathrm{m}^{3}$ and $0.34 \mathrm{MPa}$, the lowest values were $309.3 \mathrm{~kg} / \mathrm{m}^{3}$ and $0.24 \mathrm{MPa}$. High alumina cement content Gypsum insulation material compressive strength gradually increased because: the same water-cement ratio, the same curing age conditions, the strength of high-alumina cement than gypsum strength is much higher, so the high-alumina cement and the higher the content of high alumina cement in the gypsum composite cementitious material, the higher the strength of the aerated insulation material is, and the strength of the product gradually increases. The bulk density gradually increases because the plasticity strength of the gas-filled heat-retaining material increases with the increase of the content of the high-alumina cement, and the expansion of the gas-filled thermal insulation material increases with the increase of the aluminum content. Fig 1(b) shows, with the increase in the content of high alumina cement, gypsum aerosol thermal insulation material within the porosity decreased, bulk density increased, the thermal conductivity gradually increased, high-alumina When the cement content is $5 \%$, the lowest thermal conductivity is $0.073 \mathrm{~W} /(\mathrm{m} \cdot \mathrm{K})$, and the maximum thermal conductivity is $0.089 \mathrm{~W} /(\mathrm{m} \cdot \mathrm{K})$ when the content is $20 \%$.

3.2 Effect of aluminum powder content on performance of gypsum thermal insulating material

According to the test mix ratio of S2, S5, S6, S7 in Table 3, the content of aluminum powder is $0.7 \%, 0.8 \%, 0.9 \%$ and $1.0 \%$ respectively, and the content of aluminum powder in gypsum thermal insulation material Bulk density, compressive strength and thermal conductivity of the impact of its experimental are shown in Figure 2.

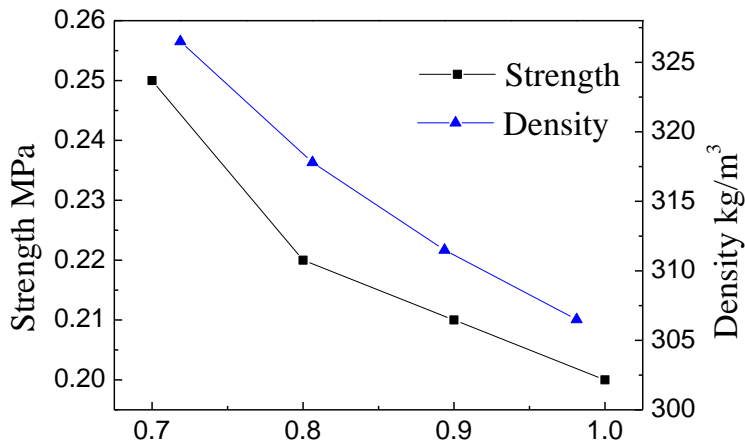

Aluminum powder content $\%$

(a)Effect of aluminum powder content on bulk density and strength of gypsum thermal insulation material 


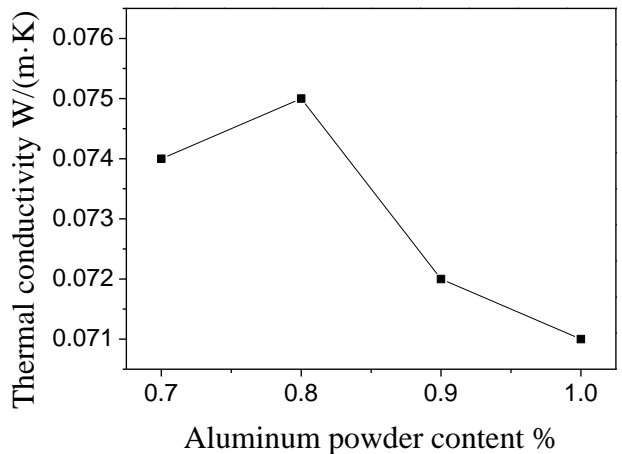

(b)Effect of aluminum powder content on thermal conductivity of gypsum thermal insulating material

Figure 2. Effect of aluminum powder content on performance of gypsum thermal insulating material

As shown in Fig 2(a), when the content of aluminum powder is between $0.7 \%$ and $1.0 \%$, the bulk density and strength of gypsum thermal insulation material decrease with the increase of aluminum powder content, and the maximum bulk density and maximum Compressive strength can reach $326.5 \mathrm{~kg} / \mathrm{m}^{3}$ and $0.25 \mathrm{MPa}$, respectively, the lowest value of $306.5 \mathrm{~kg} / \mathrm{m}^{3}$ and $0.2 \mathrm{MPa}$. This is because the chemical reaction of aluminum powder and $\mathrm{NaOH}$ aqueous solution emit hydrogen, with the increase of aluminum content, the introduction of gas volume increases, the expansion of gypsum slurry increases, the internal formation of the pores increased, resulting in insulation materials Fig 2(b) shows, with the increase of aluminum content, the thermal conductivity of gypsum thermal insulation material increases and then decreases, the maximum is $0.075 \mathrm{~W} /(\mathrm{m} \cdot \mathrm{K})$, the lowest is $0.071 \mathrm{~W} /(\mathrm{m} \cdot \mathrm{K})$.

\subsection{Effect of $\mathrm{NaOH}$ content on performance of gypsum thermal insulating material}

The content of $\mathrm{NaOH}$ was $0.2 \%, 0.3 \%, 0.4 \%$ and $0.5 \%$ respectively according to the test mix ratio of S2, S8, S9 and S10 in Table 3, and the bulk density and compressive strength of gypsum thermal insulation material Strength and thermal conductivity of the impact of its experimental are shown in Figure 3.

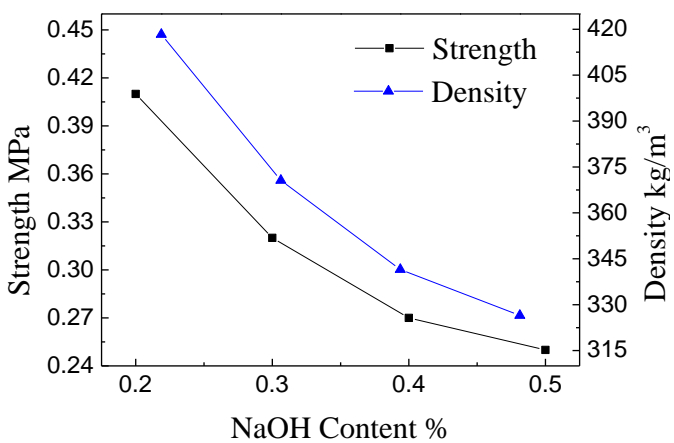

(a)Effect of $\mathrm{NaOH}$ content on bulk density and strength of gypsum thermal insulating material

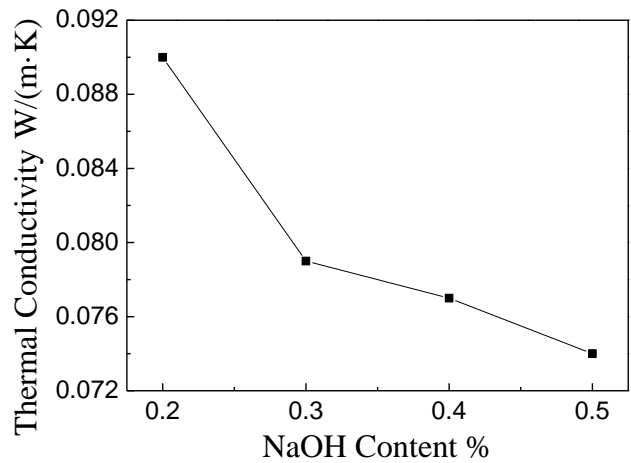

(b)Effect of $\mathrm{NaOH}$ content on bulk density of gypsum thermal insulating material

Figure 3. Effect of $\mathrm{NaOH}$ content on performance of gypsum thermal insulating material

Fig 3(a) and 3(b) shows that with the increase of $\mathrm{NaOH}$ content, the bulk density and strength of gypsum thermal insulation material gradually decreased, the maximum bulk density and the highest compressive strength can reach $418.3 \mathrm{~kg} / \mathrm{m}^{3}$ and $0.41 \mathrm{MPa}$, the lowest values were $326.5 \mathrm{~kg} / \mathrm{m}^{3}$ and $0.25 \mathrm{MPa}$. This is because the evolution of aluminum powder is the process of chemical reaction between $\mathrm{NaOH}$ solution and aluminum powder. According to the theory of chemical reaction equilibrium, the alkalinity of the solution increases and the reaction rate increases with the increase of $\mathrm{NaOH}$ content., The porosity of the material increases, so that its bulk density decreases, strength decreases, thermal conductivity decreases, the lowest thermal conductivity $0.074 \mathrm{~W} /(\mathrm{m} \cdot \mathrm{K})$.

\subsection{Effect of mixing atwer temperature on performance of gypsum thermal insulating material}

The mixing water temperature was $35^{\circ} \mathrm{C}, 40^{\circ} \mathrm{C}, 45^{\circ} \mathrm{C}$ and $50^{\circ} \mathrm{C}$ respectively according to the test mix ratio of $\mathrm{S} 2$ in Table 3 . The experimental results of The bulk density, compressive strength and thermal conductivity of gypsum thermal insulation material are shown in Figure 4.

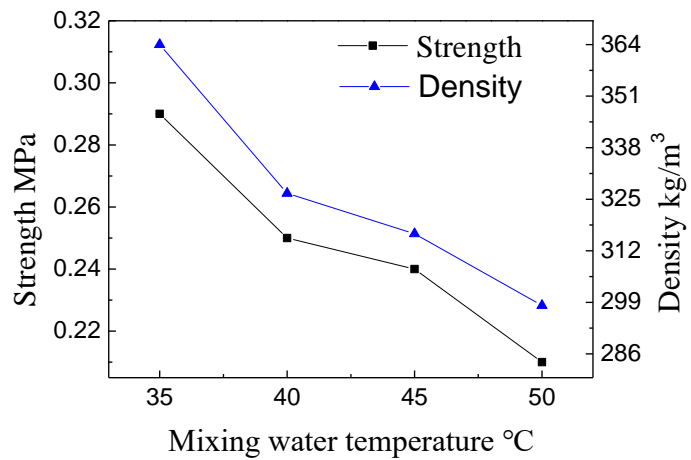

(a)Effect of mixing water temperature on bulk density and strength of gypsum thermal insulation material

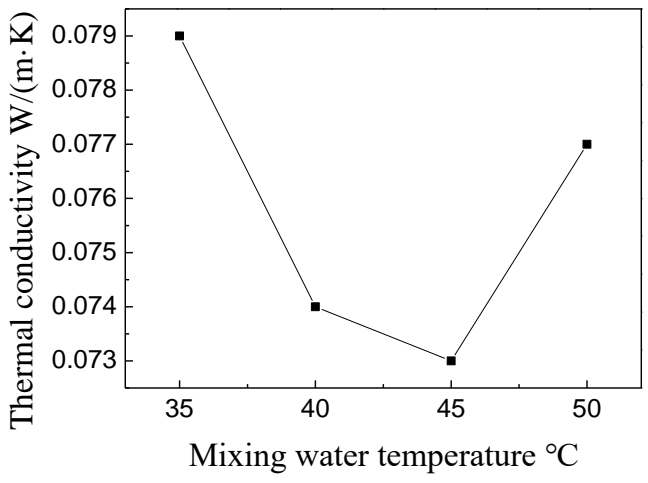

(b)Effect of mixing water temperature on thermal conductivity of gypsum thermal insulating material

Figure 4. Effect of mixing atwer temperature on performance of gypsum thermal insulating material

As shown in Fig 4(a), when the water temperature is $35-50^{\circ} \mathrm{C}$, the bulk density and strength of gypsum thermal insulation material decrease with the increase of water temperature. The maximum bulk density and maximum compressive strength can reach $364 \mathrm{~kg} / \mathrm{m}^{3}$ and $0.29 \mathrm{MPa}$, the lowest values were $298.2 \mathrm{~kg} / \mathrm{m}^{3}$ and $0.21 \mathrm{MPa}$. This is because to improve the mixing water temperature, and accelerate the reaction of aluminum and hydrogen production rate of $\mathrm{NaOH}$, in the beginning it can get a sufficient amount of gas, while the temperature increases the rate of hydration, prompting rapid thickening and swelling of the slurry, Fig 4(b) shows that with the increase of the mixing rate of the water, the volume of the bubbles increases with the increase of gas generation rate. The thermal conductivity of gypsum thermal insulation material is decreased and then increased, the maximum is $0.079 \mathrm{~W} /(\mathrm{m} \cdot \mathrm{K})$, the minimum is $0.073 \mathrm{~W} /(\mathrm{m} \cdot \mathrm{K})$

\section{Influence of different conditions on pore structure of products}

\subsection{Effect of aluminum powder content on the pore structure of gypsum insulating material}

As shown in Figure 5, the pore size of the gypsum thermal insulation material increases with the addition of aluminum powder; when the amount of aluminum powder is $0.7 \%$, the pores are smallest, the pore 
diameter is below $1 \mathrm{~mm}$, the pore diameter is uniform, The gas stagnation effect is better, at this time the strength of the thermal insulation material is the highest, the thermal conductivity is also low; with the increase in gas volume, the number of large pores, stomatal connectivity increased gradually, stomatal pore size gradually increased, stomatal distribution Uniform, irregular shape, when the aluminum content of $1.0 \%$, you can find a large number of pores connected, and the hole wall thinning, resulting in decreased strength.

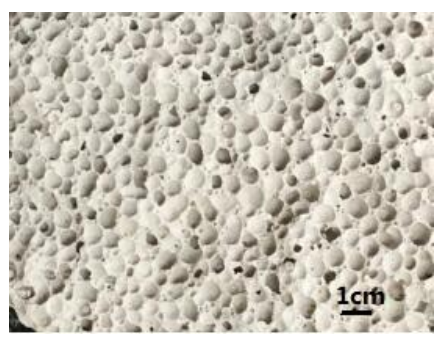

(a) $\mathrm{Al}=0.7 \%$

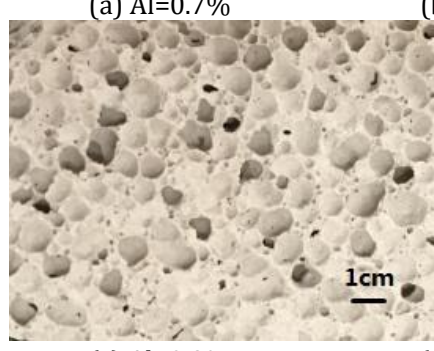

(c) $\mathrm{Al}=0.9 \%$

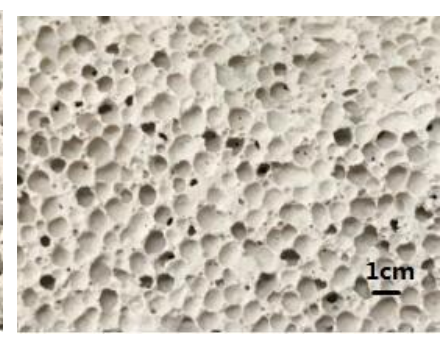

(b) $\mathrm{Al}=0.8 \%$

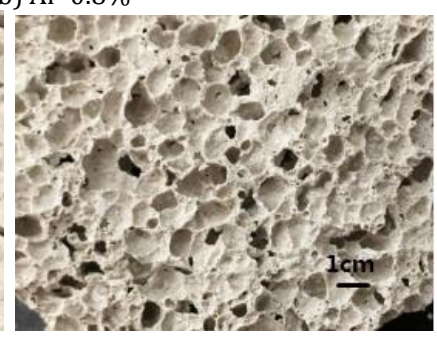

(d) $\mathrm{Al}=1.0 \%$
Fig 5 Stomatal characteristics under different aluminum powder content

\subsection{Effect of $\mathrm{NaOH}$ content on the pore structure of gypsum thermal insulating material}

As shown in Figure 6(a), when the amount of $\mathrm{NaOH}$ is small, the formation rate of gas bubbles is higher than that of the $\mathrm{NaOH}$-gypsum insulation material. The strength of the slurry is fast and the rate of bubble formation does not match with the strength of the slurry. Therefore, the pore size of the bubble is small, which is characterized by large bulk density, high strength and large thermal conductivity. When the $\mathrm{NaOH}$ content was $0.5 \%$, the bubble generation rate reached the equilibrium state with the strength of the slurry, and the pore size of the bubble was uniform and larger, and the bulk density Small, high strength, thermal conductivity is small.
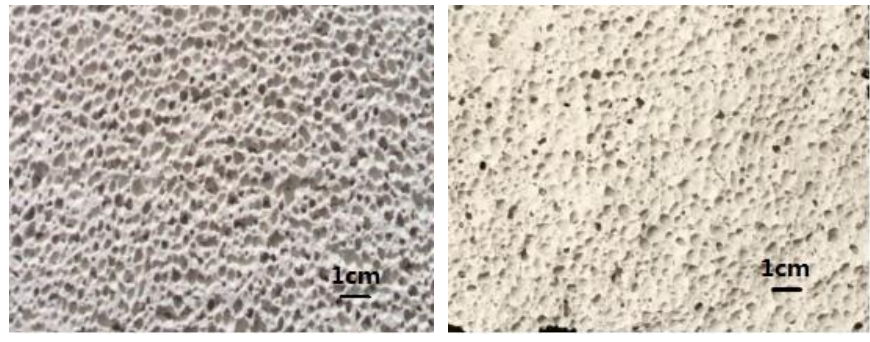

(a) $\mathrm{NaOH}=0.2 \%$

(b) $\mathrm{NaOH}=0.3 \%$
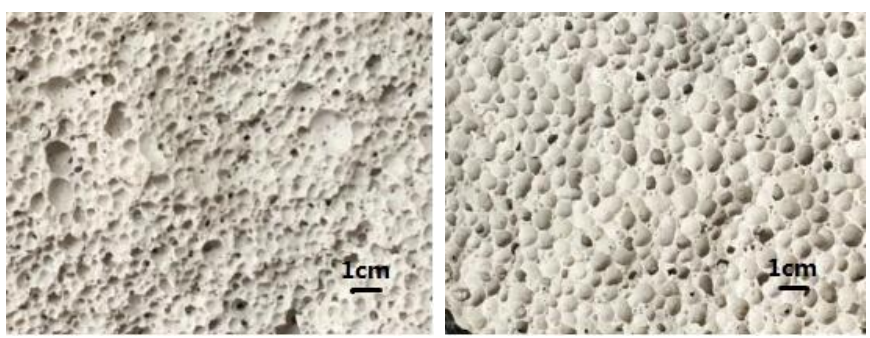

(c) $\mathrm{NaOH}=0.4 \%$

(d) $\mathrm{NaOH}=0.5 \%$

Figure 6 Stomatal characteristics under different $\mathrm{NaOH}$ levels

\section{Conclusion}

(1)With the increase of the content of high alumina cement, the bulk density and compressive strength of the gypsum thermal insulation material increased gradually, and the thermal conductivity increased gradually. With the increase of the aluminum powder content, the gypsum thermal insulation material With the increase of $\mathrm{NaOH}$ content, the bulk density and strength of gypsum thermal insulation material decreased gradually, and the thermal conductivity decreased gradually. With the increase of water temperature, the performance of gas-filled desulphurization (FGD) decreased with the increase of $\mathrm{NaOH}$ content, The bulk density and strength of the gypsum insulation material are gradually reduced, the thermal conductivity decreases first and then increases.

(2)When the water-cement ratio is 0.6 , the content of high alumina cement is $5 \%$, the content of aluminum powder is $0.7 \%$, the content of $\mathrm{NaOH}$ is $0.5 \%$ and the water temperature is $40^{\circ} \mathrm{C}$, the bulk density of gypsum thermal insulation material is $309.3 \mathrm{~kg} / \mathrm{m}^{3}$, the strength of $0.24 \mathrm{MPa}$, thermal conductivity of $0.073 \mathrm{~W} /(\mathrm{m} \cdot \mathrm{K})$, at this time of the gypsum aerosol thermal insulation material performance is better.

\section{Acknowledgements}

We would like to express our heartfelt thanks to the support of the 12th Five-Year Plan of Science and Technology Support Project, "Major Projects in Villages and Towns and Well-off Residential Buildings" (Project No. 2013BAJ10B00)

\section{References}

[1] Tang Jie. The feasibility study of solid waste comprehensive utilization project in thermal power generation company [D]. Hangzhou: Zhejiang University of Technology, 2011

[2] Zhang Deheng, Meng Lijuan, Bai Yifei. Analysis of new wall materials development and application [J]. Sichuan Cement, 2016,01: 49.

[3] Song G,Wang L,Deng L,et al. Mechanical characterization and inclusion based boundary element modeling of lightweight concrete containing foam particles [J]. Mechanics of Materials,2015,91(12) : 208 -225 .

[4] Yang Xueteng, Han Tao, Jin Xiuzhi, Wu Yanwen, Li Xiaoyu.Preparation of cast-in-place desulphurization gypsum foamed lightweight wall materials [J]. Building Materials Technology and Application, 2016,02: 13.

[5] Zhou Fei, Yang Jiujun, Wang Fang.Preparation process parameters of modified gypsum aerated material for desulphurization and its effect on performance [J]. New Building Materials, 2012,06: 20-23 + 29 .

[6] Lao Yousheng. Desulfurization gypsum modified aerated materials [D] Tianjin University of Urban Construction, 2014.

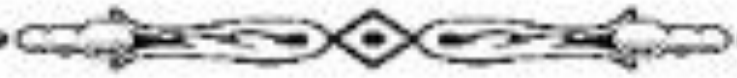

